\title{
UNAPREĐENJE PROCESA SKLADIŠTENJA U ORGANIZACIJI „VRTLARI“ DOO MALI IĐOŠ
}

\section{IMPROVEMENT OF THE STORAGE PROCESS IN THE ORGANIZATION "VRTLARI" LTD MALI IĐOŠ}

\author{
Biljana Brkljač, Fakultet tehničkih nauka, Novi Sad
}

\section{Oblast - INŽENJERSKI MENADŽMENT}

Kratak sadržaj - Predmet rada jeste prikaz procesa skladištenja u organizaciji „Vrtlari“ DOO iz Malog Iđoša. Nakon teorijskih osnova iz oblasti logistike, kompletnog procesa skladištenja, kao i metoda i tehnika koje su korišćcene u radu detaljno je predstavljen $i$ analiziran proces vođenja skladišnog poslovanja ove organizacije. $U$ završnici rada za uočene probleme definisane su adekvatne mere unapređenja.

Ključne reči: Skladištenje, logistika

\begin{abstract}
The subject of the paper is a presentation of the storage process in the organization "Vrtlari" Ltd from Mali Iđoš. After the theoretical foundations in the field of logistics and the complete storage process, as well as the methods and techniques used in the paper, the process of managing the storage business of this organization is presented in detail and analyzed. At the end, adequate improvement measures were defined for the identified problems.
\end{abstract}

Keywords: Storage process, logistics

\section{UVOD}

Skladištenje predstavlja držanje proizvoda u optimalnim skladišnim uslovima do slanja u proizvodnju ili dalju distribuciju, tačnije, premošćavanje vremenske distance. Osnova uloga skladišta jeste čuvanje skladištene robe u za to predviđenim uslovima. Time se obezbeđuje i osigurava nesmetano odvijanje procesa proizvodnje, tačnije besprekidan tok istog, što se postiže dovoljnom količinom zaliha na skladištu.

Međutim, veoma često dolazi do problema kada se sam proces skladištenja ne obavlja na adekvatan način pa u tom slučaju skladište ne predstavlja prostor u kome se u svakom trenutku radnik može i mora brzo snalaziti, već predstavlja neuredno i za efikasan rad neprihvatljivo radno mesto, čiji raspored i organizacija ne doprinose lakom snalaženju i poslovanju bez dodatnih troškova. Upravo u tim situacijama, kada neorganizacija skladišta donosi bespotrebne troškove, poslodavac se mora pozabaviti načinima organizacije i optimizacije skladišta putem najpopularnijih alata i metoda čija je primena nadaleko poznata.

\section{NAPOMENA:}

Ovaj rad proistekao je iz master rada čiji mentor je bio dr Stevan Milisavljević, vanr. prof.

\section{LOGISTIKA}

Kako je navedeno u [1], a prema [4] u literaturi postoji mnogo definicija termina, koji objašnjavaju pojam logistike i logističkog koncepta. Izraelski vojni istoričar i teoretičar, Martin Van Creveld, rekao je da logistika, sa aspekta terminologije vojne literature, podrazumeva umetnost razmeštanja vojske i njeno redovno snabdevanje.

Američka organizacija, odnosno udruženje stručnjaka za upravljanje lancima snabdevanja, Council of Supply Chain Management Professionals (CSCMP) dala je svoje viđenje logistike i navela da je logistika: „Proces planiranja, implementacije i upravljačkih procedura za efikasno i efektivno transportovanje i skladištenje robe, uključujući i usluge i sa njima povezane informacije, od mesta nastanka do mesta potrošnje“" [5]. Takođe, jedan od vodećih teoretičara u ovoj oblasti, Michel Baudin, definiše logistiku na sledeći način: „Logistika se sastoji od svih operacija potrebnih za isporučivanje roba ili usluga, osim proizvodnje roba ili konkretnog pružanja usluga" (Baudin, 2004).

\section{SKLADIŠNI PROCES}

Prema [2] skladištenje je ona funkcija logistike koja obavlja "čuvanje" robe (proizvoda, poluproizvoda) u, ili između, mesta nastanka i mesta potrošnje. Ova funkcija je nužna pošto je nemoguće uskladiti intenzitet potrošnje (konzumiranja) nekog proizvoda sa dinamikom njegove proizvodnje, niti je moguće uskladiti pojedine proizvodne operacije međusobno.

Stoga se proizvodni proces najčešće odvija na sledeći način: definisanje proizvodnog plana - nabavka potrebnih dobara - skladištenje nabavljenih dobara do trenutka otpočinjanja proizvodnje - transport robe iz skladišta $u$ proizvodni pogon - obrada na prvoj mašini (prva operacija) - skladištenje između dve operacije - transport do druge mašine - obrada na drugoj mašini - skladištenje do sledeće operacije ... obrada na poslednjoj mašini (poslednja operacija) - transport do skladišta - isporuka na tržište.

Iz ovoga je vidljivo da se praktično u svakom trenutku, neki proizvod nalazi ili na nekoj mašini gde se obavlja neka obrada ili se nalazi u fazi uskladištenja, bilo da se radi o kratkotrajnom skladištenju između dve operacije (može trajati i samo nekoliko minuta) ili da se radi o skladištenju u trajanju od nekoliko dana, pa čak i meseci. 


\section{METODOLOGIJA - PRIKAZ METODA I TEHNIKA KOJE ĆE SE KORISTITI ZA ANALIZU PROBLEMA I PREDLOG MERA UNAPREĐENJA}

\subsection{Dijagram uzrok - posledica (Ishikawa dijagram)}

Kako je rečeno u [3] Ishikawa dijagram predstavlja jednostavnu i vrlo korisnu metodu za sagledavanje ŠTO VIŠE MOGUĆIH UZROKA koji dovode do POSLEDICE / PROBLEMA koji se analizira.

Analiza UZROK - POSLEDICA zasniva se na principu uzročnosti. Uzročnost je odnos između jednog događaja (uzrok) i drugog događaja (efekat), gde se drugi događaj shvata kao posledica prvog.

Vizuelni prikaz uzroka koji ova metoda pruža odgovara izgledu riblje kosti pa se otuda ovaj dijagram često naziva i dijagram riblja kost (FISHBONE DIAGRAM).

\subsection{Gantogram}

Gantogram je, u osnovi, dijagram koji se sastoji od koordinatnog sistema, u kojem je horizontala vreme, a vertikala resursi na kojima se odvijaju pojedini radni nalozi, po operacijama i vremenom početka i završetka svake operacije. Vremenski interval se određuje shodno vrsti proizvodnje, odnosno dužini proizvodnog ciklusa.

To je, ustvari, metoda grafičkog prikazivanja informacija koja se često koristi za utvrđivanje rasporeda aktivnosti. Tipični Ganttov dijagram grafički prikazuje greške u zadatku, vreme potrebno za kompletnu izradu zadatka kao i procenat urađenog dela zadatka. Svaki stubić (linija) predstavlja jedan zadatak s vremenskim vrednostima, a redovi sadržaj zadataka.

\section{O ORGANIZACIJI}

Vrtlari DOO su porodična organizacija, pre desetak godina osnovana kao malo porodično, poljoprivredno gazdinstvo koje se bavilo proizvodnjom paradajza i paprike. Sa dugogodišnjim iskustvom u tradicionalnoj proizvodnji voća i povrća, pre par godine započeli su projekat proširenja proizvodnje i prerade proizvoda sa njihovih plantaža.

Uz kvalitetne sirovine i potencijal kojim raspolažu, angažovali su najbolje tehnologe, dizajnere i za dve godine dostigli nivo savremenog pogona velikih kapaciteta i odličnih receptura.

Prioritet su dali konceptu tradicionalne proizvodnje sa ciljem da se dobije zdrav proizvod pri čemu se teži očuvanju boje, ukusa i mirisa. U kontrolisanoj proizvodnji objedinjavaju sve procese ovog ciklusa od samog sađenja biljaka do krajnjeg ubiranja plodova i prerade. Svi proizvodi su bez konzervansa i bilo koje druge vrste aditiva.

Celokupan asortiman sastoji se od slatkih i slanih proizvoda koji su podeljeni na sedam grana: sokovi od paradajza, ajvari, extra džemovi, kašasti sokovi, slatka, zanatski namazi za sir i potaži.

\subsection{Proces skladištenja}

Proces skladištenja u okviru organizacije Vrtlari DOO započinje dolaskom potrebnih sirovina i repromaterijala $\mathrm{u}$ poluimprovizovano, interno, centralizovano skladište $u$ neposrednoj blizini samog proizvodnog pogona.

Skladište organizacije Vrtlari DOO nalazi se u nastavku proizvodne hale i nije u vlasništvu organizacije već ga ista zakupljuje. Skladište je podeljeno u komore, od kojih organizacija zakupljuje dve, veličine orijentaciono 20x10m. Ostale komore su u zakupu drugih proizvođača. Usled povećanja obima proizvodnje nastaje i potreba za većim skladištem od postojećeg.

Sam prostor oko skladišta, a i unutar samog skladišta, deluje prilično neuređeno. Roba unutar skladišta nije grupisana i tako složena na određene pozicije, već i ambalaže i proizvoda ima u gotovo svim delovima skladišta bez neke preterane organizacije.

Neretko se može desiti da su putanje kretanja radnika i samih mašina za manipulaciju neprohodne. Pored neprohodnosti usled neorganizacije uskladištene robe zabunu stvaraju i transportne rute koje nisu ocrtane ni $\mathrm{u}$ jednoj komori.

Komore su građene od panelnih zidova i opremljene su rashladnim uređajima koji održavaju temperaturu do $+4^{\circ} \mathrm{C}$. Rashladni uređaji u komorama samo održavaju temperaturu uskladištenih proizvoda, kratkotrajno uskladištenih poluprerađenih proizvoda ili sirovine. Međutim, ovi rashladni uređaji ne mogu zamrzavati sirovine $\mathrm{i}$ za to se koriste eksterne hladnjače koje organizacija zakupljuje.

$\mathrm{S}$ obzirom na činjenicu da se proizvodnja odvija sukcesivno, tačnije zavisi od same sezone određenog voća ili povrća, u velikom broju slučajeva pristigle sirovine odmah po obavljenoj kvantitativnoj i kvalitativnoj kontroli ulaze $\mathrm{u}$ proces proizvodnje, stoga se iste privremeno skladište u sam proizvodni pogon odnosno deo pogona predviđen za pakovanje i etiketiranje proizvoda. Po pravilu, u delu pogona predviđenom za pakovanje i etiketiranje ostavlja se po jedna paleta od svih proizvoda za koje se po planu zna da će tog dana biti isporučene.

Sirovine koje ne ulaze odmah po prispeću u proces obrade ili sirovine koje tog dana nisu stigle biti obrađene po predviđenom planu, odlažu se, kratkotrajno, na održavanje temperature, $u$ jednu od dve komore skladišta koje je u zakupu ove organizacije.

Nakon završenog procesa proizvodnje proizvedene količine koje su već unapred rezervisane za hitnu isporuku ostaju u samom pogonu do trenutka isporuke, dok se ostatak gotovih proizvoda lageruje u skladište.

Pored navedenih sirovina, poluproizvoda i gotovih proizvoda u komorama se skladišti ambalaža u vidu kutija za pakovanje proizvoda.

U situacijama kada je u planu neka veća porudžbina određenog proizvoda za čiju proizvodnju će biti potrebno više radnih dana, u tom slučaju se potrebna sirovina (voće ili povrće) skladišti u hladnjačama koje nisu u vlasništvu organizacije, te ih ista mora zakupiti.

Svi procesi zaprimanja pristiglih sirovina, repromaterija i ambalaže, skladištenja i izdavanja gotovih proizvoda iz 
skladišta obavljaju se uglavnom ručno tj. neautomatizovano.

Proces inventarisanja obavlja se pojedinačnim brojanjem svih zapremljenih jedinica u skladištu i za to su zaduženi radnici.

Radnici pored svojih svakodnevnih obaveza i porasta obima proizvodnje, uopšte širenja poslovanja, ne stižu da ovaj proces obave na $100 \%$ precizan način. Stiče se zaključak da ovakav način prebrojavanja i uspostavljanja stanja na zalihama nije najadekvatniji ni za zaposlene ni za organizaciju.

Od opreme koju poseduju za manipulaciju robom po proizvodnom pogonu i skladištu poseduju samo ručni viljuškar koji je u vlasništvu organizacije. Za sve zahtevnije prenose robe po skladištu, utovare i istovare iznajmljuju veći viljuškar - paletar.

\section{ANALIZA PROBLEMA - PRIKAZ PROBLEMA I ANALIZA PRIMENOM POMENUTIH METODA I TEHNIKA}

Kao najveći problemi procesa skladištenja ove organizacije izdvajaju se:

- Neuređen izgled samog skladišta i prilaza skladištu

- Nebezbedno skladište (neosigurano, bez transportnih ruta)

- Nedostatak skladišnog prostora (male dimenzije skladišta)

- Nedostatak hladnjače u sklopu skladišnog prostora

- Neadekvatno praćenje stanja robe u skladištu (zastareli

- ručni sistem brojanja prilikom inventara)

- Manjak alata za manipulaciju robom

Svi prethodno nabrojani problemi sa uzrocima istih grupisani su i prikazani putem Ishikawa dijagrama (slika 1).

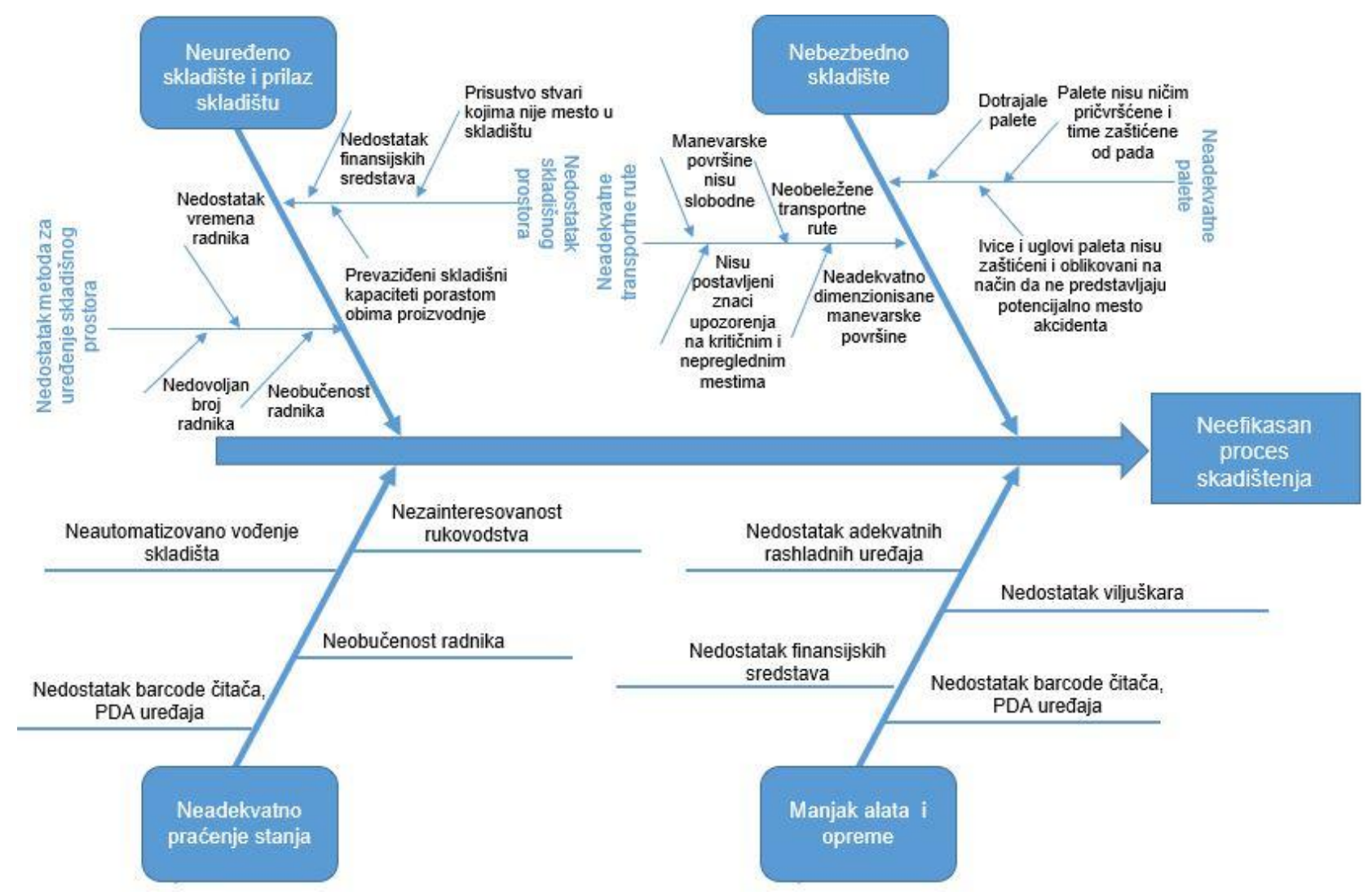

Slika 1. Ishikawa dijagram

\section{MERE UNAPREĐENJA - PRIKAZ, EFEKTI}

$\mathrm{Na}$ osnovu teorijskih postavki, snimka trenutnog stanja organizacije i procesa skladištenja i analiziranih problema izvedene su mere unapređenja čijim bi potencijalnim uvažavanjem rad organizacije Vrtlari DOO, njihova i efikasnost njihovih procesa bila na znatno višem nivou. Rezultati celokupnog rada treba da koriste organizaciji kao ulaz za buduće planiranje poslovanja, kao temelj za donošenje odluka od velike važnosti i, pre svega, kao osnova za dalje napredovanje.

\section{Iznajmiti veće skladište sa hladnjačom (do $\left.1000 \mathrm{~m}^{2}\right)$}

Da bi organizacija nastavila nesmetano da funkcioniše i, pre svega, da bi imala prostora da napreduje potrebno je iznajmljivanje većeg skladišnog prostora koji u sebi sadrži i hladnjaču. Hladnjača je neizostavni uslov prilikom odabira novog skladišnog prostora, kako bi organizacija u budućnosti izbegla troškove iznajmljivanja iste $\mathrm{u}$ situacijama kada zbog obima posla ne može $u$ jednom danu da obradi svu pristiglu sirovinu.

Pored hladnjače, kao jednog od uslova prilikom odabira, novi skladišni prostor trebao bi i lokacijski da odgovara potrebama organizacije s obzirom na to da je većina kupaca skoncentrisana na prostoru Novog Sada i Beograda.

2. Organizovati obuku zaposlenih za primenu 5 s metode uređenja prostora 
Zaposleni ove organizacije moraju proći obuku novog načina čišćenja i uređenja prostora kako bi istu mogli i da primene u poslovanju.

3. Organizovati sređivanje skladišnog prostora i prilaza skladištu prema pravilma $5 \mathrm{~S}$ metode

Zaposleni će biti obučeni da svoj radni prostor, pre svega skladište, dovedu i odžavaju na odgovarajućem nivou. Biće osposobljeni da poboljšaju urednost radnog mesta nalazeći posebno mesto za sve i ostavljajući sve na svom mestu $\mathrm{i}$ to se odnosi na oslobađanje od svega što nije potrebno, pravilno razmeštanje potrebnih stvari (ograničiti zalihe), čišćenje i spolja i iznutra, definisanje pravila za održavanje prva 3S i održavanje svega toga na duže staze.

Ono čemu će 5S metoda najviše doprineti jeste svakako organizacija paleta po grupi proizvoda u novim paletnim regalima (više o tome u nastavku). Naime, palete će biti grupisane prema vrsti proizvoda po principu FIFO. $\mathrm{Na}$ mestima predviđenim za određenu grupu proizvoda biće napravljene adekvatne oznake kako ni u kom slučaju ne bi došlo do zabune i ostavljanja nekog drugog proizvoda na mestu koje za to nije predviđeno.

\section{Ocrtati precizne i pravilno dimenzionisane transportne} rute u skladištu

Trenutni način obeležavanja transportnih ruta u skladištu ne postoji što predstavlja veliku opasnost od povreda na radnom mestu. I radnici i transportne mašine kreću se istim putanjama bez ikakvih obeležja. Pored povreda na radu ovakav način izvođenja procesa skladištenja usporava i jedne i druge u obavljanju svakodnevnih obaveza.

5. Napraviti visoke paletne regale u skladištu za slaganje paleta

Trenutni princip slaganja paleta jedne na drugu je nebezbedno i nepregledno rešenje. Skladištenje paleta u visoke paletne regale predstavlja sigurniji način i doprinosi lakšem pristupu svakoj paleti. Paletni regali su izvedeni u obliku jednostavne metalne konstrukcije.

\section{Zameniti dotrajale palete novim}

Drvene palete same po sebi imaju rok trajanja, naročito kada su korišćene u uslovima vlažnih i hladnih prostorija. Neretko u njima dođe do loma ambalaže i svaki od proizvoda ostavlja svoj trag. Naposletku, nakon toliko prenošenja, slaganja i korišćenja ne mogu večno trajati. Palete su važan deo pravilnog skladištenja i čuvanja proizvoda stoga se iste $\mathrm{s}$ vremena na vreme moraju promeniti.

7. Automatizovati proces vođenja skladišta uvođenjem WMS sistema

WMS rešenja - sistemi za upravljanje skladištem su informaciona poslovna rešenja koja podržavaju i optimizuju proces upravljanja robom od momenta ulaska u skladište, sve do izlaska robe.

8. Kupiti viljuškar (paletar)

Kako je do sada organizacija iznajmljivala i trošila veliku količinu finansijskih resursa na iznajmljivanje viljuškara kupovinom istog ostvariće znatne uštede. S obzirom na povećanje obima posla, samim tim i povećanom potrebom za ovakvom vrstom opreme u skladištu do povraćaja investicije doći će u kratkom vremenskom periodu.

\section{ZAKLJUČAK}

Cilj rada bio je, pre svega uvideti, na osnovu snimka trenutnog stanja organizacije, kakav je princip vođenja poslova skladištenja $u$ organizaciji Vrtlari DOO. Na osnovu rezultata rada jasno je da je prostor za unapređenje skladišnog poslovanja ove organzacije veliki, ali se isto tako može zaključiti da bi organizacija uz relativno mala ulaganja mogla postići velike rezultate i dugoročno efikasnije poslovanje. Stalnim ulaganjem u svoje poslovanje, u svoje zaposlene i građenje imidža društveno i ekološki odgovorne organizacije, Vrtlari DOO je na dobrom putu da to i ostvari.

Problemi i uzroci istih predstavljeni su putem Ishikawa dijagrama. Kao problemi koji zahtevaju primarno rešavanje izdvojili su se mali prostor skladišta i nedostatak hladnjače, kao i neautomatizovano vođenje skladišta. Ovakvi problemi $u$ toku obavljanja svakodnevnih aktivnosti predstavljaju veliku prepreku za napredovanje ovoj organizaciji.

$\mathrm{Na}$ osnovu gantograma i odrađene finansijske analize jasno se vidi da bi organizacija primenom definisanih mera unapređenja i uz minimalna ulaganja $u$ proces skladištenja ostvarila velike uštede, olakšala rad svojim zaposlenima i dugoročno unapredila svoje poslovanje. Cilj je pre svega motivisati ljude da ono što donose predstojeće promene i implemetirane metode primenjene kao dobrobit kompaniji prepoznaju kao dugoročni boljitak i njih kao sastavnog dela organizacije.

Organizacija Vrtlari DOO ima veliki potencijal da dostigne još veći uspeh na domaćem, ali i na inostranom tržištu. U trendu domaće, zdrave, tradicionalno pripremane i pre svega ukusne hrane ova organizacija prepoznaje svoju šansu za uspeh.

\section{LITERATURA}

[1] N.Brkljač, Uticaj primene faktora uspešnosti povratne logistike i barijera za implementaciju na performanse organizacije - Doktorska disertacija, str. 31-35, Novi Sad, 2017.

[2] I. Beker, \& D. Stanivuković, Integralna sistemska podrška materijal sa predavanja. Novi Sad, 2007.

[3] I. Beker, \& M. Vuković, (2014 / 2015). Projektovanje i analiza postupaka održavanja - Materijal sa predavanja. Novi Sad, 2014/2015.

[4] Baudin, M, Lean Logistics: The Nuts and Bolts of Delivering Materials and Goods. New York: Productivity Press, 2004.

[5] Vitasek, K, Supply Chain Management Terms and Glossary. Council of Supply Chain Management Professionals, 2013.

[4] http://media.etsbor.edu.rs/2011/02/011 gantogram.pdf (pristupljeno u julu 2021.)

\section{Kratka biografija:}

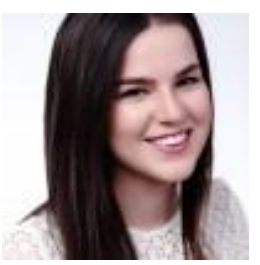

Biljana Brkljač rođena je u Bačkoj Topoli 1997. god. Diplomski rad na Fakultetu tehničkih nauka, iz oblasti Logistike, Zadovoljstvo korisnika uslugom kurirskih službi na teritoriji Republike Srbije odbranila je 2020. god kontakt: biljabrkljac3@gmail.com 